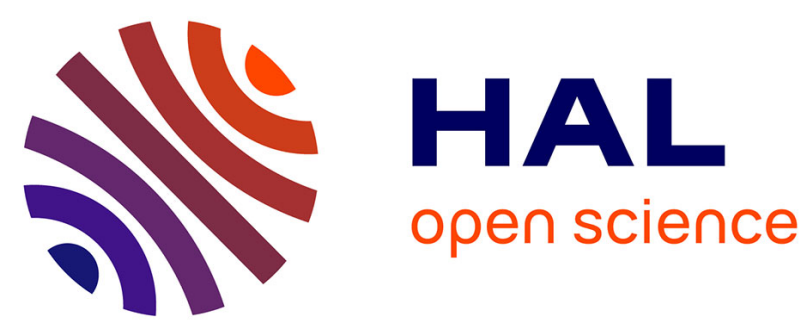

\title{
Controlled Modification of Polymer Surfaces through Grafting of Calix[4]arene-Tetradiazoate Salts
}

Ludovic Troian-Gautier, Daniel E. Martinez-Tong, Julie Hubert, François Reniers, Michele Sferrazza, Alice Mattiuzzi, Corinne Lagrost, Ivan Jabin

\section{- To cite this version:}

Ludovic Troian-Gautier, Daniel E. Martinez-Tong, Julie Hubert, François Reniers, Michele Sferrazza, et al.. Controlled Modification of Polymer Surfaces through Grafting of Calix[4]arene-Tetradiazoate Salts. Journal of Physical Chemistry C, 2016, 120 (40), pp.22936-22945. 10.1021/acs.jpcc.6b06143 . hal-01395477

HAL Id: hal-01395477

https://hal-univ-rennes1.archives-ouvertes.fr/hal-01395477

Submitted on 5 Jan 2017

HAL is a multi-disciplinary open access archive for the deposit and dissemination of scientific research documents, whether they are published or not. The documents may come from teaching and research institutions in France or abroad, or from public or private research centers.
L'archive ouverte pluridisciplinaire HAL, est destinée au dépôt et à la diffusion de documents scientifiques de niveau recherche, publiés ou non, émanant des établissements d'enseignement et de recherche français ou étrangers, des laboratoires publics ou privés. 


\title{
Controlled Modification of Polymer Surfaces
}

\section{Through Grafting of Calix[4]arene-Tetradiazoate}

\section{Salts}

Ludovic Troian-Gautier, ${ }^{\dagger}$ Daniel E. Martínez-Tong, ${ }^{\perp}$ Julie Hubert, ${ }^{\ddagger}$ François Reniers, ${ }^{,}$Michele Sferrazza, ${ }^{\perp}$ Alice Mattiuzzi, ${ }^{\dagger,}{ }^{*}$ Corinne Lagrost ${ }^{£, *}$ and Ivan Jabin ${ }^{\dagger}$

† Laboratoire de Chimie Organique, Université Libre de Bruxelles (ULB), CP 160/06, 50 avenue F.D. Roosevelt, 1050 Brussels, Belgium.

${ }^{\perp}$ Département de Physique, Faculté des Sciences, Université Libre de Bruxelles (ULB), CP 223, Campus de la Plaine, Boulevard du Triomphe, 1050 Brussels, Belgium.

${ }^{£}$ Institut des Sciences Chimiques de Rennes UMR n ${ }^{\circ}$ 6226, Université de Rennes 1 and CNRS Equipe MaCSE, Campus de Beaulieu, 35042 Rennes cedex, France.

$\ddagger$ Chimie Analytique et Chimie des Interfaces, Université Libre de Bruxelles (ULB), CP 255, Campus de la Plaine, boulevard du Triomphe, 1050 Brussels, Belgium.

\begin{abstract}
An attractive methodology based on diazonium chemistry has been developed for the surface modification of polymers such as polypropylene (PP), polyethylene terephthalate
\end{abstract}


(PET) and polystyrene (PS). The grafting procedure involves the in situ formation of diazoates in basic aqueous solution. The reactivity of calix[4]arene-tetradiazonium salts and a classical aryldiazonium salt was examined through comparative studies on gold and polymer surfaces. The surfaces were analyzed with a combination of techniques such as AFM, XPS and ellipsometry. The results highlighted the fact that the calix[4]arene molecules are grafted as a robust and uniform monolayer both on gold and polymer surfaces, allowing a fine control over surface modification. Furthermore, the chemical post-functionalization of the grafted calix platforms equipped with carboxylic-pendant groups was successfully performed with either an amine or an alcohol. These results open real possibilities in the controlled immobilization on polymers of a wide variety of molecules of interest such as biomolecules or chromophores and in the tailoring of polymers properties.

\section{Introduction}

The functionalization of surfaces through reaction with diazonium salts is now a widely recognized method. ${ }^{1-3}$ It has been successfully implemented in various fields such as sensing, ${ }^{4-7}$ biosensing, ${ }^{8,9}$ catalysis, ${ }^{10,11}$ microelectronics, ${ }^{12}$ carbon nanotubes modification, ${ }^{13-16}$ batteries,${ }^{17-19}$ etc. and could be met nowadays in industrial applications including inks/paints, medical stents or thin layers in microelectronics. ${ }^{20}$ The attractiveness of the diazonium functionalization is mainly due to the formation of a robust interface and to its great versatility as it can be applied to all forms of carbon (diamond, glassy carbon, HOPG, carbon felts, fullerene, carbon nanotubes, graphene, carbon black), to various metallic surfaces (from noble to industrial metals, $\mathrm{Au}, \mathrm{Pt}, \mathrm{Cu}$, $\mathrm{Ni}, \mathrm{Fe}, \mathrm{Zn}$, stainless steel), to semiconductors ( $\mathrm{Si}, \mathrm{SiGe}, \mathrm{Ge}, \mathrm{GaAs})$ and to oxides (Indium Tin Oxide, $\mathrm{SnO}_{2}, \mathrm{TiO}_{2}, \mathrm{SiO}_{2}, \mathrm{Fe}_{3} \mathrm{O}_{4}$ nanoparticles). ${ }^{1}$ Aryldiazonium cations can be easily reduced 
into the corresponding aryl radicals by loss of nitrogen, and these very reactive aryl radicals are able to react with a surface, forming a strong surface-carbon bond. The aryl radicals can be produced by electrochemical reduction at conducting substrates, by chemical reduction with the use of reducing agents such as $\mathrm{H}_{3} \mathrm{PO}_{2},{ }^{21}$ ascorbic acid, ${ }^{22}$ or metals such as zinc or iron, combined with sulfuric or hydrochloric acid ${ }^{23-25}$ as well as by photochemical reduction in the presence of a sensitizer. ${ }^{26}$ Spontaneous reaction with the surface involving solvent-induced homolytic dediazonation $^{27,28}$ or aqueous acidic solution for gold modification, ${ }^{29}$ or involving the substrate itself in case of reducing metals such as copper, ${ }^{30,31} \operatorname{iron}^{32}$ and nickel ${ }^{33}$ have also been described. Although rarely reported, an interesting mild route consists in using a basic aqueous solution (e.g. aqueous sodium hydroxide) for promoting a spontaneous grafting of aryl radicals issued from the decomposition of diazoates. ${ }^{34-36}$ Diazonium salts react with strong nucleophiles at the terminal nitrogen to give azo adducts, and reaction with hydroxide ions yields transient diazohydroxides, which are rapidly deprotonated to diazoates $\left(\mathrm{Ar}-\mathrm{N}=\mathrm{N}-\mathrm{O}^{-}\right){ }^{37}$ The diazoates spontaneously dediazonize to give aryl radicals that were recently shown to react with iron, gold, $\mathrm{Fe}_{3} \mathrm{O}_{4}$ or carbon surfaces. ${ }^{34-36}$

The chemical functionalization of polymer surfaces is often required for attaching bioactive compounds,${ }^{38}$ for microfluidics applications ${ }^{39,40}$, for altering their adhesion, ${ }^{41}$ anti-biofouling ${ }^{42}$ or wetting properties, ${ }^{43}$ etc. Despite of being easy to process, fast and highly versatile, the modification of polymer surfaces by reaction with aryl radical has been little explored: fluorinated polymers, ${ }^{40,44}$ membranes, ${ }^{45,46}$ polymethylmethacrylate, ${ }^{43}$ polyvinylchloride ${ }^{26}$ cyclic olefin copolymer, ${ }^{47}$ polyethyleneterephthalate, ${ }^{48}$ have been modified by the reduction of a diazonium salt. However, in none of these works, the surface grafting was achieved by using the sodium hydroxide-based process. As far as we know, the reactivity of diazoates toward 
polymeric surfaces has never been examined. Yet this route could be of great interest for polymers, avoiding the use of reducing chemical agents.

Unless special conditions or specifically-designed diazonium compounds are used, ${ }^{49-55}$ the formation of monolayers with diazonium chemistry remains challenging. Indeed, the aryl units already grafted can further react with the highly reactive unreacted aryl radicals, leading to disorganized multilayers structures ${ }^{56-58}$ rather than to monolayers (Figure 1b), in contrast with the spontaneous adsorption of alkanethiols onto coinage metal (Pt, $\mathrm{Au}, \mathrm{Ag}, \mathrm{Cu}$ ), which is known to form self-assembled monolayers (SAMs) (Figure 1a) ${ }^{59}$ In this context, we recently reported the use of calix[4]arene-tetradiazonium salts to obtain robust monolayers on conducting surfaces such as gold and carbon (Figure 1c) ${ }^{60,61}$ Due to the unique macrocyclic structure of the calixarene skeleton, the formation of disorganized multilayers is prevented, and a dense and compact monolayer is easily formed. Furthermore, the grafted calix[4]arenes constitute versatile platforms that can be easily post-functionalized via classical chemical coupling reactions. This post-functionalization may allow a very accurate spatial control of the immobilization of chemical species (e.g. DNA, peptides, NPs, etc.) in close proximity to the surface and thus may afford surfaces exploitable notably in (bio-)sensing and catalysis.

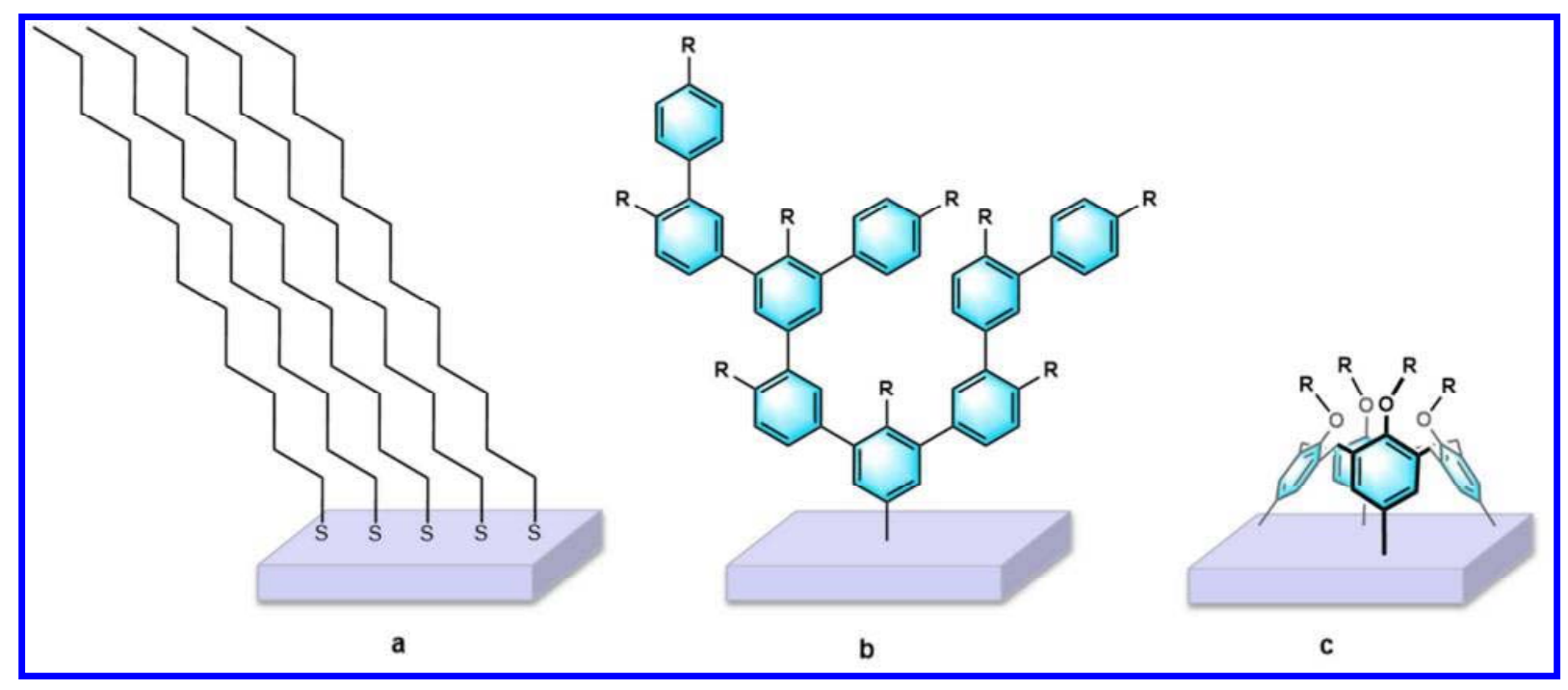

ACS Paragon Plus Environment 
Figure 1. Examples of strategies for surface modification: a) self-assembled monolayers of linear alkanethiols, b) "cauliflower" structure obtained with classical aryldiazoniums, c) monolayer obtained with calix[4]arene-tetradiazoniums.

In order to further develop a grafting methodology exhibiting a fine control at the molecular scale that could be applicable on both conducting and insulating materials, we have investigated the grafting of calix[4]arene-tetradiazoate salts on gold and on polymers such as polypropylene (PP). Since the reactivity of diazoates toward polymers is still unknown, the grafting was first examined with gold surfaces as a reference surface material. It is demonstrated that the reported strategy allows the straightforward modification of all type of alkali-resistant surfaces by a robust, uniform and easily post-functionalizable monolayer.

\section{Experimental}

Chemicals. All solvents and reagents were at least of reagent grade quality and were purchased either from Alfa Aesar, Sigma-Aldrich or Acros organics. 4,4,4-trifluorobutylamine 97\% was purchased from Fluorochem, 4,4,4-trifluoro-1-butanol 98\% was purchased from Sigma-Aldrich. Anhydrous DMF and $\mathrm{CHCl}_{3}$ were obtained from Acros organics. Gold coated silicon wafer $\left(1000 \AA\right.$ layer thickness) and $\mathrm{TBAPF}_{6}$ (electrochemical grade) were purchased from Sigma-Aldrich. Polypropylene (biaxially oriented, $50 \mu \mathrm{m}$ ), polyethylene terephthalate (optically clear, $36 \mu \mathrm{m}$ ), and polystyrene (crystal transparent amorphous, $1.2 \mathrm{~mm}$ ) surfaces were purchased from Goodfellow. The typical size of the surfaces reported in this paper was $1 \mathrm{~cm}^{2}$. Each grafting experiment was repeated three times to ensure reproducibility. Ultrapure water was obtained via a Millipore Milli-Q system (18.2 M $2 . \mathrm{cm})$. The syntheses of calix[4]arene- 
tetraanilines and the corresponding diazonium salts $\mathbf{1}$ and $\mathbf{2}$ as well as compound $\mathbf{3}$ were adapted from literature (Figure 2). ${ }^{60,62,63}$

Caution! Although we have not encountered any problem, it is noted that diazonium salts are potentially explosive and should be handled with appropriate precautions.

Electrochemical grafting. Gold surfaces were first immersed in a "piranha" solution $\left(\mathrm{H}_{2} \mathrm{SO}_{4} / \mathrm{H}_{2} \mathrm{O}_{2}\right.$ 3:1) and sonicated for 10 minutes. Caution! Piranha solution is a very strong oxidant and should be handled very carefully. They were then washed with ultrapure water and dried under argon atmosphere. The electrochemical grafting was performed using an Autolab PGSTAT 100 potentiostat, by applying a constant potential of $-0.5 \mathrm{~V}$ vs SCE for 5 minutes, in $0.1 \mathrm{M} \mathrm{TBAPF}_{6}$ anhydrous acetonitrile containing $1 \mathrm{mM}$ solution of compound 2 or $\mathbf{3}$. Once the grafting was achieved, the surfaces were thoroughly rinsed with acetonitrile, $0.1 \mathrm{M}$ hydrochloric acid and water. Sonication was applied each time for ten minutes. The surfaces were finally dried using an argon flow.

Chemical grafting using sodium hydroxide. Gold surfaces were first immersed in a "piranha" solution $\left(\mathrm{H}_{2} \mathrm{SO}_{4} / \mathrm{H}_{2} \mathrm{O}_{2}\right.$ 3:1) and sonicated for 10 minutes. Polypropylene, polyethylene terephthalate, and polystyrene surfaces were cleaned with isopropanol under sonication for 10 minutes, washed with ultrapure water and dried using an argon flow. The surfaces were then dipped in a $5 \mathrm{mM}$ solution of the diazonium salt $(\mathbf{1}, \mathbf{2}$ or $\mathbf{3})$ in aqueous $0.1 \mathrm{M}$ sodium hydroxide for 16 hours (unless specifically precised), without stirring in order to avoid any mechanical frictions of the surface with the magnetic stirrer bar (a minimum volume of solution is used). Once the grafting was achieved, all the surfaces were thoroughly washed with water. Then, those modified with compound $\mathbf{1}$ were successively rinsed with acetonitrile, dichloromethane and toluene, whereas those modified with compound 2 or 3 were rinsed with acetonitrile, $0.1 \mathrm{M}$ 
hydrochloric acid and water. Note that the polystyrene surfaces, whether modified or not, were rinsed with acetonitrile and hexane as these surfaces are soluble in dichloromethane and toluene. Sonication was applied each time for ten minutes. The surfaces were then dried under argon flow.

Post-functionalization using EDC/NHS. Polypropylene surfaces modified with compound 2 were placed in a sealed tube and covered with $40 \mathrm{mM}$ EDC solution in MES buffer at $\mathrm{pH}$ 6.9. After 1 hour, an equal amount of an 8 mM NHS solution in MES buffer at pH 6.9 was added, giving rise to a final concentration of $20 \mathrm{mM}$ EDC and $4 \mathrm{mM}$ NHS in MES buffer. The mixture was allowed to react for 2 hours. After being washed with water and dried under an argon flow, the activated surfaces were then immersed in a $0.2 \mathrm{mM}$ solution of the desired compound $(4,4,4-$ trifluorobutylamine or 4,4,4-trifluoro-1-butanol) in dichloromethane. After 4 hours, the surfaces were rinsed with dichloromethane, acetonitrile and toluene. Sonication was applied each time for 10 minutes. The surfaces were then dried using an argon flow.

Atomic Force Microscopy (AFM). AFM measurements were carried out in a Multimode microscope, equipped with a Nanoscope IIIa controller (Bruker). PPP-NCL-W probes (Nanosensors) were used for all the experiments. The topography characterization of the films was carried out using the tapping protocol, where the probe was driven close to its resonant frequency (about $150 \mathrm{kHz}$ ) at an amplitude set-point of $1 \mathrm{~V}$. The thickness characterization of the films was performed adapting a previously reported protocol. ${ }^{64}$ The probe was engaged in contact mode, with a constant deflection set-point of $0.1 \mathrm{~V}$, and a $1 \mu \mathrm{m}^{2}$ area was scanned (for both gold and polymer surfaces). In particular, under these conditions, it was possible to remove the molecular layer without damaging the supporting gold substrate. Afterwards, a $5 \mu \mathrm{m}^{2}$ area was scanned in tapping mode and the mean value of the step between the two different zones 
was quantified. The procedure was repeated at different points of the substrate to check the homogeneity. All the AFM images were analyzed using the Nanoscope Analysis 1.5 software (Bruker).

Ellipsometry measurements. Layers thicknesses on gold were measured in a HS-190 spectroscopic ellipsometer, equipped with a VB-250 control module (J. A. Woollam Co Inc). A spectral range from $300 \mathrm{~nm}$ to $1200 \mathrm{~nm}$, in steps of $10 \mathrm{~nm}$ was scanned at an incident angle of $45^{\circ}$. The following values were taken for gold: $n_{s}=0.203, k_{s}=3.431$, while for the molecular layers: $n_{s}=1.5, k_{s}=0$, as previously reported. ${ }^{60}$

XPS measurements. XPS analysis was performed on a Physical Electronics PHI-5600 photoelectron spectrometer. Survey scans were used to determine the elemental chemical composition of the surface. Narrow-region photoelectron spectra were used for the chemical study of the $\mathrm{C} 1 \mathrm{~s}$. The spectra were acquired using the $\mathrm{Mg}$ anode $(1253.6 \mathrm{eV})$ operating at $300 \mathrm{~W}$. Wide surveys were acquired at a pass-energy of $187.5 \mathrm{eV}$ with a five-scans accumulation (time/step: $50 \mathrm{~ms}$, eV/step: 0.8) and high-resolution spectra of the $\mathrm{C} 1 \mathrm{~s}$ peaks were recorded at a pass-energy of $23.5 \mathrm{eV}$ with an accumulation of 5 scans (time/step: $150 \mathrm{~ms}$, eV/step: 0.05). Spectral calibration was determined by setting $\mathrm{C} 1 \mathrm{~s}$ at $285 \mathrm{eV}$. The atomic concentration for surface composition was estimated using the integrated peaks areas; the peaks area were normalized by the manufacturer-supplied sensitivity factor $\left(\mathrm{S}_{\mathrm{C}}=0.205, \mathrm{~S}_{\mathrm{F}}=1, \mathrm{~S}_{\mathrm{O}}=0.63, \mathrm{~S}_{\mathrm{N}}=\right.$ $\left.0.38, \mathrm{~S}_{\mathrm{Si}}=0.17\right)$. The core level $\mathrm{C} 1 \mathrm{~s}$ spectra were peak-fitted using the CasaXPS software (Casa Sofware, Ltd., version 2.3.16).

\section{Results and discussions}


The experiments were conducted with three different diazonium salts 1-3 (Figure 2). Calix[4]arene-tetradiazonium 1 was used for characterization purpose as the $\mathrm{CF}_{3}$ group leads to a very characteristic signal in XPS spectroscopy. Calix[4]arene-tetradiazonium 2 was chosen because its terminal carboxylic groups allow a post-functionalization of the grafted monolayer. The grafting of diazonium 3 was investigated for comparison purpose with the related tetradiazonium 2. As previously shown on gold and carbon surfaces, ${ }^{60,61}$ the electrografting of calix[4]arene-tetradiazonium salts $\mathbf{1}$ and $\mathbf{2}$ leads to the formation of dense and compact monolayers. A study using gold substrates was first undertaken to determine whether similar results could be obtained from the grafting in aqueous hydroxide solution. Polymers surfaces were then used as substrates for performing the hydroxide-based grafting of the calix[4]arene platforms.

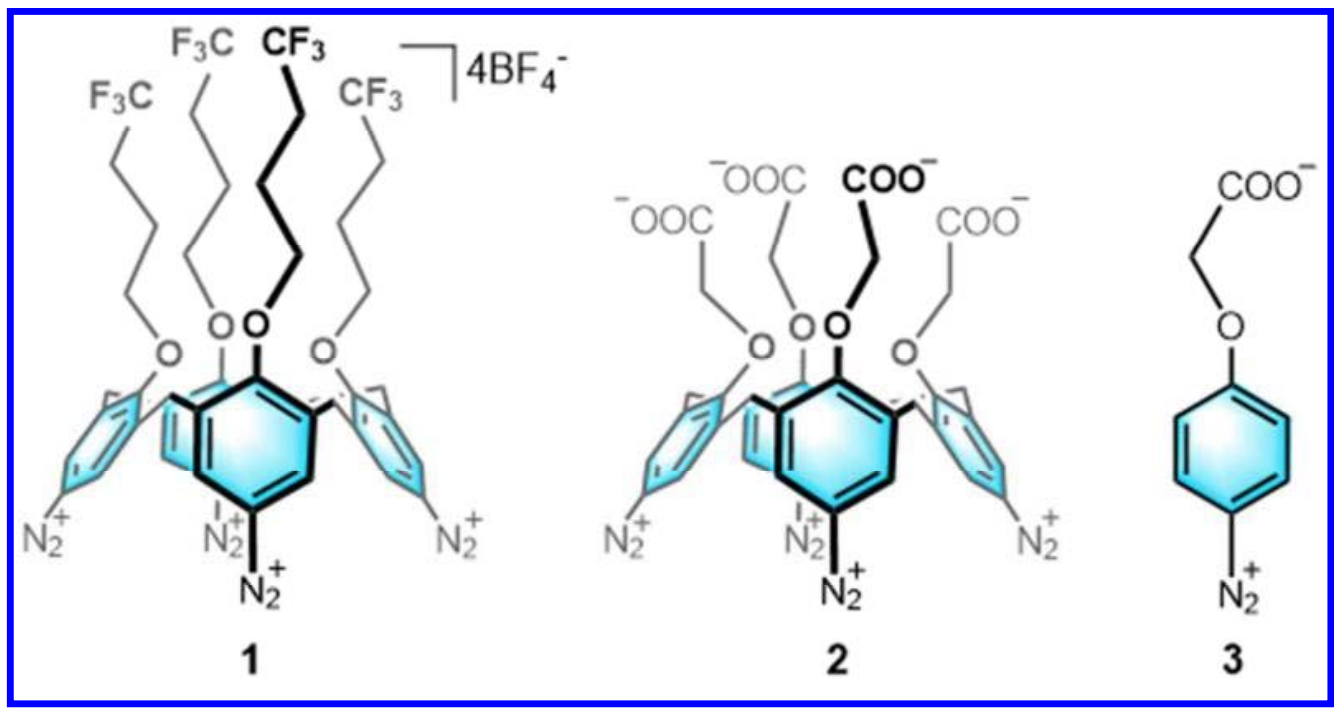

Figure 2. Diazonium salts 1-3 used for surface modification.

Grafting on gold surfaces. The grafting of diazonium salts $\mathbf{2}$ and $\mathbf{3}$ (dediazonized either by electrochemical reduction or in aqueous hydroxide solution) was performed on gold surfaces for comparison purposes. The electrochemical grafting was achieved by applying a constant potential of $-0.5 \mathrm{~V}$ vs SCE during 5 minutes. The grafting promoted by sodium hydroxide was 
realized by immersing the surfaces in an alkaline solution $(\mathrm{pH}=13)$ of the desired diazonium compound. In all cases, the modified gold surfaces were thoroughly rinsed with acetonitrile, 0.1 $\mathrm{M}$ hydrochloric acid and water (sonication was applied each time for 10 minutes). The surfaces were then analyzed using atomic force microscopy and ellipsometry to estimate the thickness of the deposited layer.

Figures 3 and 4 show AFM topography images of gold substrates grafted with compounds 2 and 3 respectively, through electrochemical reduction (Figures $\mathbf{3 b}$ and $\mathbf{4 b}$ ) and by using sodium hydroxide (Figures 3c and 4c). The AFM height images of bare gold surfaces are also represented for comparison purposes (Figures 3a and 4a). A granular surface with a mean roughness value close to $1.4 \mathrm{~nm}$ can be observed for the bare gold surface. After grafting with compounds 2 or 3 , the surfaces roughness mean values evolved little (less than $20 \%$ ), showing that the grafted layer fits the morphology of the bare gold substrates, indicating hence the formation of a thin layer. In all cases, one can observe the formation of a uniform layer as no important material accumulation or depletion zones are observed. The AFM images after scratching a $1 \mu \mathrm{m}^{2}$ area as well as the corresponding surface profiles are represented in Figures 3b-c and 4b-c, respectively. Using the height difference among both areas of the surface profile, a similar thickness value of $1.5 \pm 0.3 \mathrm{~nm}$ could be estimated for the surfaces modified with compound 2 through both electrochemical and sodium hydroxide promoted dediazonization (Figures 3b-c). Ellipsometry measurements also lead, within experimental errors, to an identical thickness value of $1.9 \pm 0.5 \mathrm{~nm}$ in both cases. Considering the height of calix[4] arene $2(0.74$ $\mathrm{nm}^{65}$ ) plus the length of the gold-carbon bond (c.a. $0.2 \mathrm{~nm}^{66}$ ) on the one hand and the similar values found in both grafting methodologies on the other hand, these thickness estimations show that a monolayer of calix[4]arene is obtained from the hydroxide-based process, as demonstrated 
in our earlier work using electrochemical reduction of calix[4]arene-tetradiazonium. Worth is noting that the specific structure of the calix[4]arene moiety presents no available sites for the formation of a multilayer. To further support this conclusion, the compound 3 that can produce multilayered films as the ortho position is available for reaction, ${ }^{1}$ was also grafted using the two strategies. For the surfaces modified with compound $\mathbf{3}$, the height difference calculated from the surface profile gives a thickness estimated value of $3.5 \pm 0.5 \mathrm{~nm}$, for both grafting procedures. This thickness value is further confirmed by the ellipsometry measurements, which lead to values close to $3.0 \pm 0.7 \mathrm{~nm}$. This thickness would correspond to 3-4 layers, providing that the molecules are not tilted and aligned across a straight axis.

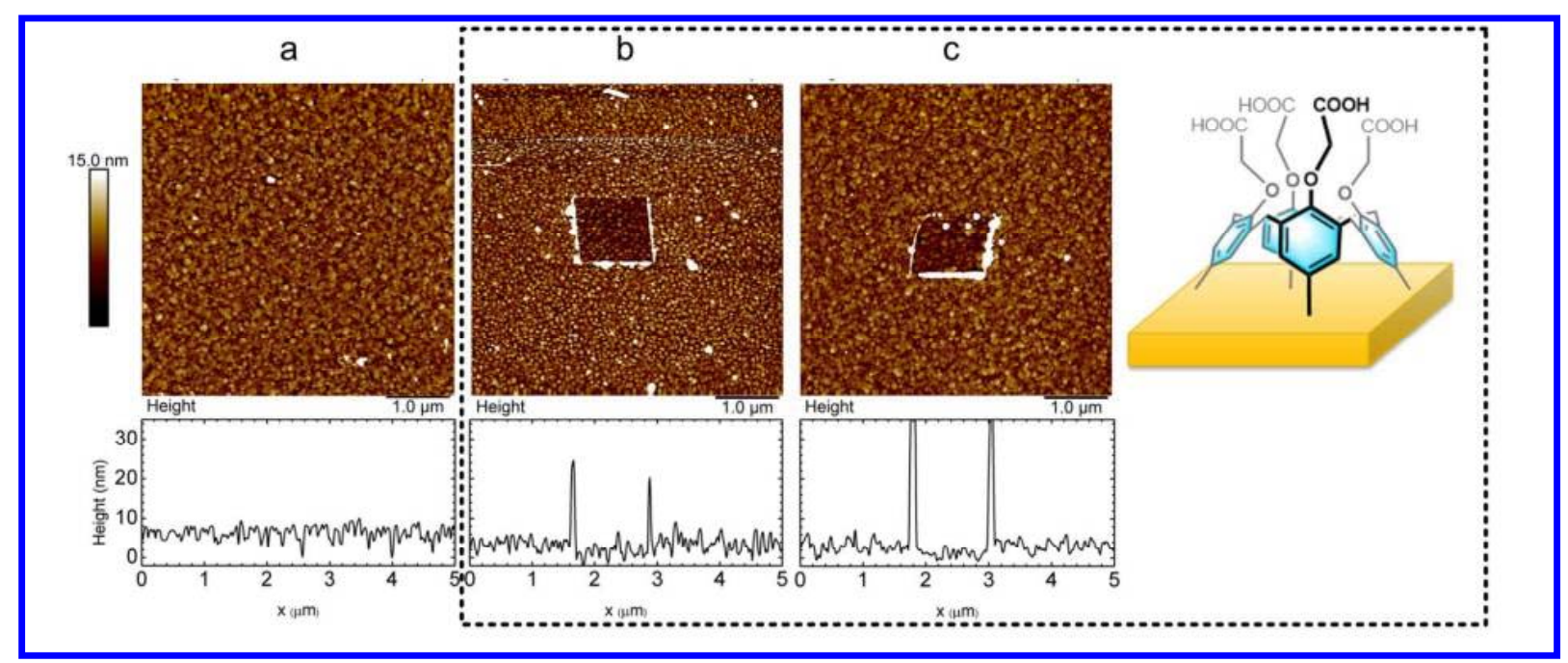

Figure 3. AFM images of a) the bare gold surface after scratching a $1 \mu \mathrm{m}^{2}$ area b) compound 2 grafted on gold by electrochemistry and c) compound $\mathbf{2}$ grafted on gold using sodium hydroxide. b) and c) also include the scratching of a $1 \mu \mathrm{m}^{2}$ area as well as the corresponding surface height profile. 


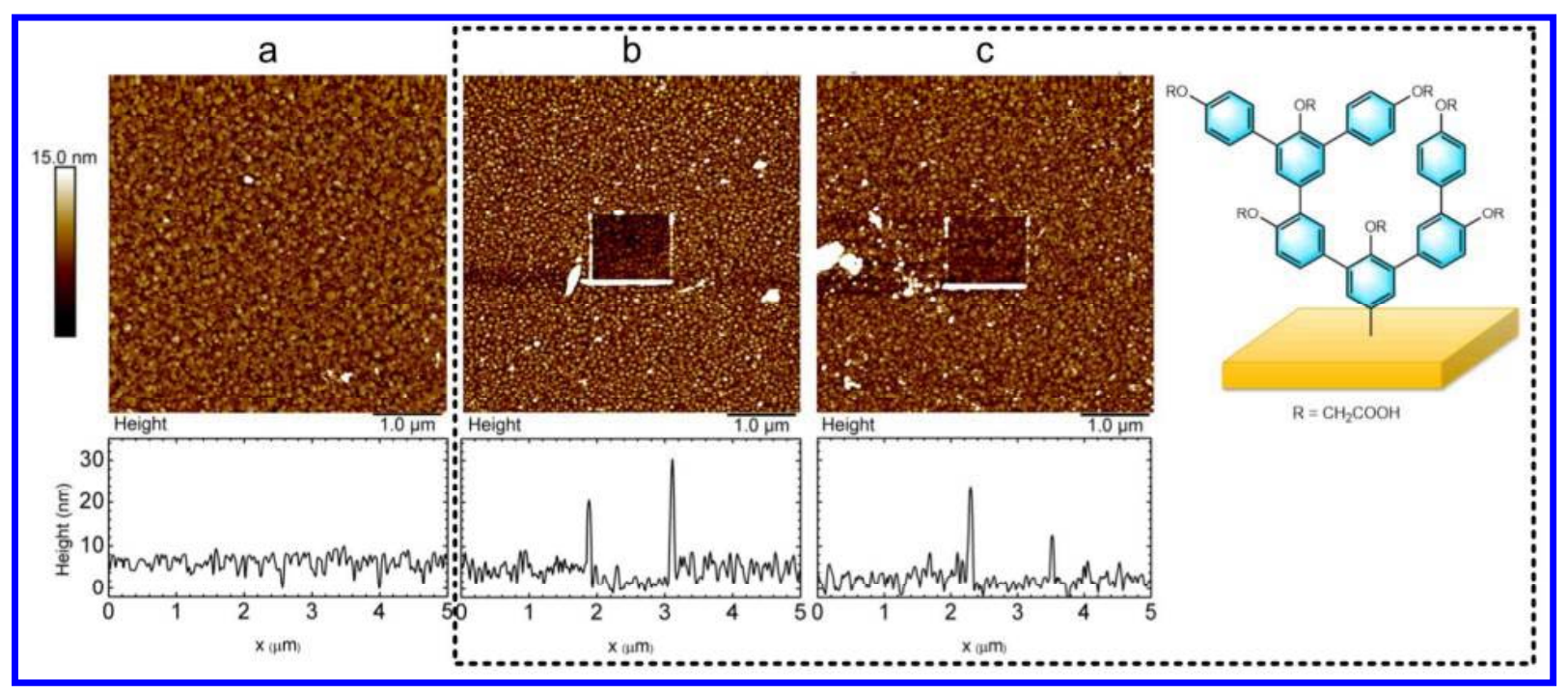

Figure 4. AFM images of a) the bare gold surface after scratching a $1 \mu \mathrm{m}^{2}$ area b) compound 3 grafted on gold by electrochemistry and c) compound $\mathbf{3}$ grafted on gold using sodium hydroxide. b) and c) also include the scratching of a $1 \mu \mathrm{m}^{2}$ area as well as the corresponding surface height profile.

These results clearly indicate that the grafting by electrochemistry as well as by using sodium hydroxide allows the formation of a compact, uniform, robust layer on gold substrate. In agreement with previously reported results, ${ }^{1,60,61}$ a monolayer is obtained by grafting compound $\mathbf{2}$ whereas compound $\mathbf{3}$ leads to a multilayer. The grafting procedure using sodium hydroxide being validated on gold, we next moved to the modification of polymers.

Grafting on polypropylene surfaces. Grafting of compounds 1-3 on polypropylene surfaces was achieved by immersing the polymer surface in an aqueous $0.1 \mathrm{M}$ sodium hydroxide solution containing $5 \mathrm{mM}$ of the desired diazonium salt. The surfaces modified from compounds $\mathbf{2}$ and $\mathbf{3}$ were then thoroughly rinsed with acetonitrile, $0.1 \mathrm{M}$ hydrochloric acid and water whereas surfaces modified from compound $\mathbf{1}$ were washed with water and thoroughly rinsed with 
acetonitrile, dichloromethane and toluene. Sonication was applied each time for ten minutes. The surfaces were then analyzed using atomic force microscopy, ellipsometry and X-ray photoelectron spectroscopy.

Figure 5 shows AFM height images of grafted polypropylene surfaces using compounds 1, 2 and $\mathbf{3}$ and the sodium hydroxide-based procedures. For comparison, an AFM image of a bare PP surface which was only treated with sodium hydroxide is also shown (Figure 5a). It is worth noting that the relatively soft bare PP surfaces display a large roughness ( $\mathrm{rms} \approx 8-9 \mathrm{~nm}$ ). The ungrafted PP surface shows grooves. After grafting, a continuous surface was observed and no signs of agglomeration neither depletion were found. The grooves were still visible but the blurred aspect qualitatively suggests the formation of a thin organic film at the polymer surfaces. The modified surfaces from compounds $\mathbf{1}, \mathbf{2}$ and $\mathbf{3}$ show mean roughness values of 3.7, 4.0 and $3.5 \mathrm{~nm}$, respectively, that correspond to a decrease of almost $45 \%$ in comparison to the bare polypropylene substrate, indicating that the organic molecules were indeed grafted on polypropylene surfaces. The modified polypropylene surfaces were then scratched using the same protocol than that used for the gold modified surfaces. It should be emphasized that scratching experiments are particularly difficult to carry out and we systematically damaged the surface, even by drastically lowering the deflection set-point. It was literally impossible to perform analyzable scratching experiments with surfaces modified with compounds $\mathbf{1}$ and 2 . However, for surfaces modified with compound $\mathbf{3}$, the procedure caused weaker damages on the supporting PP than for the other modified surfaces. This allows to measure the height profile for surfaces modified with compound $\mathbf{3}$ equal to $9 \pm 2 \mathrm{~nm}$ (Figure 5c and Figure S9). This thickness value is about 3 times that found for the corresponding modified gold surface. Importantly, this measurement is only a coarse estimation because i) of the high roughness of the bare PP, and ii) 
even if the supporting substrate is less strongly scratched than for surfaces modified with compounds $\mathbf{1}$ or $\mathbf{2}$, it could be modified down to a few nanometers. The fact that the thickness of the layers deposited on PP cannot be quantified, in the case of the grafting from $\mathbf{1}$ and $\mathbf{2}$ deserves being further commented. Indeed, when scratching with the AFM probe, the polypropylene substrate was heavily damaged, even at the lowest possible deflection set-point (thus the lowest possible applied force), indicating that the grafted organic layer is probably very thin. As a result, the thickness of the organic layer cannot be determined by this technique. Unfortunately, the ellipsometry technique that requires a flat reflective surface cannot be applied to measure the thickness of the film deposited onto the PP surfaces. Nevertheless, the qualitative observations made by the AFM techniques point to the formation of very thin films in the case of PP modified with the hydroxide-based grafting of compounds $\mathbf{1}$ and $\mathbf{2}$.

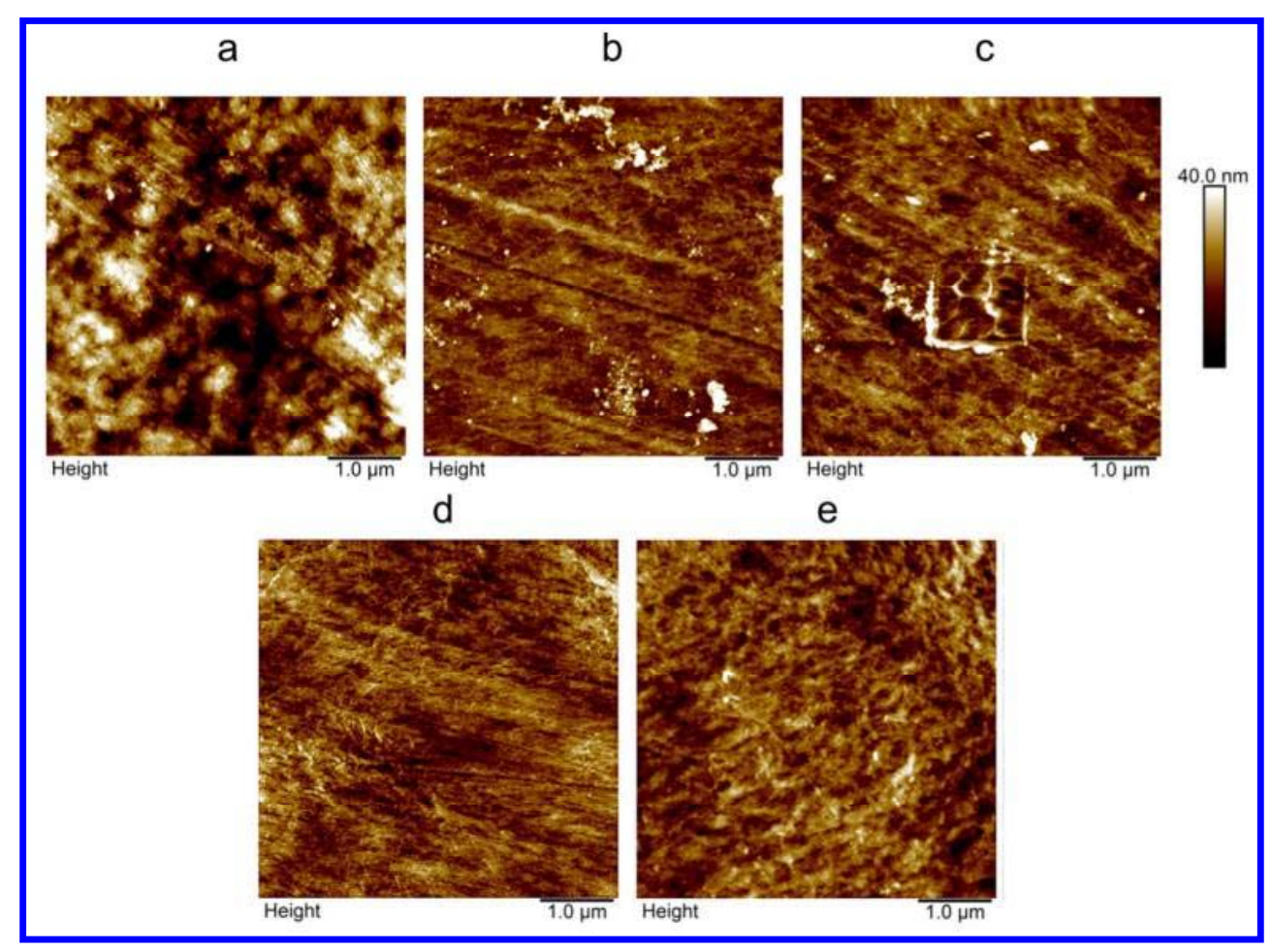


Figure 5. AFM topography images of polypropylene surfaces a) bare, treated with sodium hydroxide only; b) modified by compound 3 ; c) modified by compound $\mathbf{3}$ and after scratching a 1 $\mu \mathrm{m}^{2}$; d) modified by compound 1 ; e) modified by compound 2

Further evidence of the grafting of calix[4]arene-tetradiazonium salts on PP was obtained by X-ray photoelectron spectroscopy (XPS) (Figure 6). The compound 1 was specifically used to assess the success of the surface modification, the $\mathrm{CF}_{3}$ group being used as a chemical tag (see also Tables S1 and S2). The survey spectrum shows the presence of carbon C1s (280-296 eV, 75 $\%$ atom), oxygen $\mathrm{O} 1 \mathrm{~s}(533 \mathrm{eV}, 9 \%$ atom), fluorine $\mathrm{F} 1 \mathrm{~s}(688.5 \mathrm{eV}, 13 \%$ atom) and a small amount of nitrogen at $400 \mathrm{eV}$ that might either be due to the formation of a small proportion of azo groups derived from the diazonium salts or to contamination, as already reported in the literature. ${ }^{30,66-69}$ The absence of peaks at $403.8 \mathrm{eV}$ indicates that no diazonium compounds remain adsorbed at the surface. The presence of the F1s photoelectron peak obviously suggests the grafting of the calix[4]arene with $\mathrm{CF}_{3}$ termini at the PP surface. The $\mathrm{C} 1$ s core level spectrum could be decomposed into different components (Figure 6 right, Table S2). The main component centered at $285 \mathrm{eV}$ can be attributed to the carbon atoms of the calix[4]arene core as well as the carbon atoms from the PP substrate. The component at $286.3 \mathrm{eV}$ is mostly assigned to the ether links present in the calix[4]arene core. Also, this component partly contributes to oxidized contamination species, as well as the component at $287.3 \mathrm{eV}$; these components were detected on the bare PP substrate, being soaked or not in the hydroxide solution prior to analysis (see SI). The component at $293 \mathrm{eV}$ corresponds to the $\mathrm{CF}_{3}$ groups and further confirms the grafting of compound 1 on PP surface. 

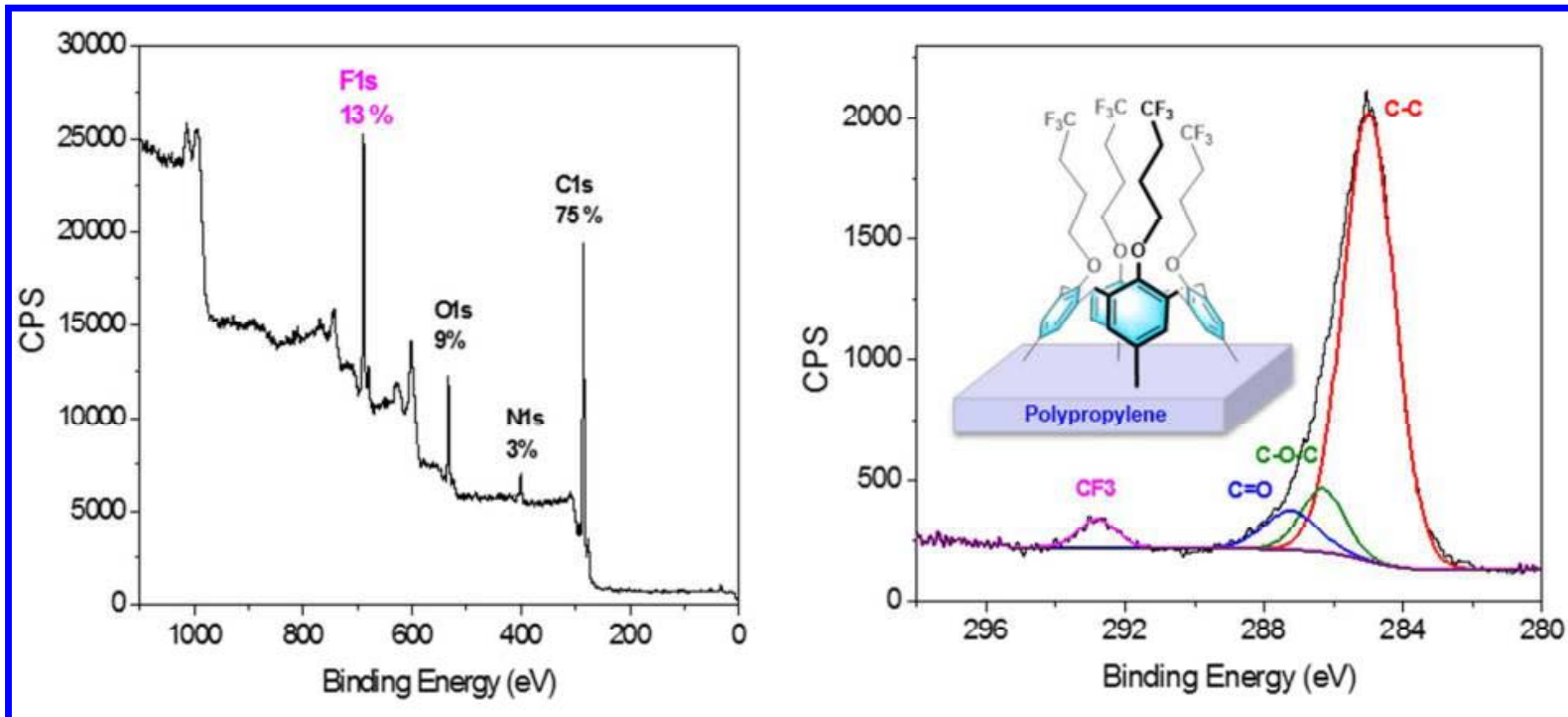

Figure 6. XPS spectra of (left) polypropylene modified with compound 1 and (right) corresponding $\mathrm{C} 1$ s core level spectrum.

The AFM observations combined to the XPS measurements suggest that a monolayer of calixarenes is deposited on the surface of polypropylene through the spontaneous dediazonization of the calix[4]arene-tetradiazonium cations in the hydroxide solution. Yet, the diazoate species are rather unstable and their radical decomposition are reported to be fast $^{34,35,70,71}$. It was then of interest to check if the functionalization of the PP surface could occur over shorter times than $16 \mathrm{~h}$, i.e. whether functionalization process could indeed occur from dediazonization of diazoate. The hydroxide-based chemical grafting with compound $\mathbf{1}$ was also performed by soaking the surface for $1 \mathrm{~h}$ or $4 \mathrm{~h}$. After a thorough rinsing, the resulting surfaces were characterized by XPS spectroscopy. In both cases, elemental species $\mathrm{C}, \mathrm{O}$ and $\mathrm{F}$ are detected (see Figure S8). The atomic ratio (\%) are close to those found for PP modified for $16 \mathrm{~h}$ (Table S3). An immersion time of $1 \mathrm{~h}$ is sufficient to allow for the functionalization of the PP surfaces, which is highly consistent with the relatively short lifetime of diazoates. 
Post-functionalization of the modified polypropylene surfaces. The PP surfaces modified with compound $\mathbf{2}$ could undergo a chemical post-functionalization reaction by using the reactive carboxylic terminal groups. As a proof of concept, such a post-functionalization was investigated with $\mathrm{CF}_{3}$-containing compounds in order to allow the straightforward XPS characterization of the post-functionalized PP surfaces. The pendant carboxylic groups were first converted into the corresponding activated esters by EDC/NHS in MES buffer at a $\mathrm{pH}$ of 6.9 (Figure 7). The resulting activated surfaces were then engaged in a reaction either with 4,4,4-trifluorobutylamine or with 4,4,4-trifluoro-1-butanol. Prior to their spectroscopic analyses, the surfaces were thoroughly rinsed with acetonitrile, dichloromethane and toluene (sonication was applied each time for 10 minutes).

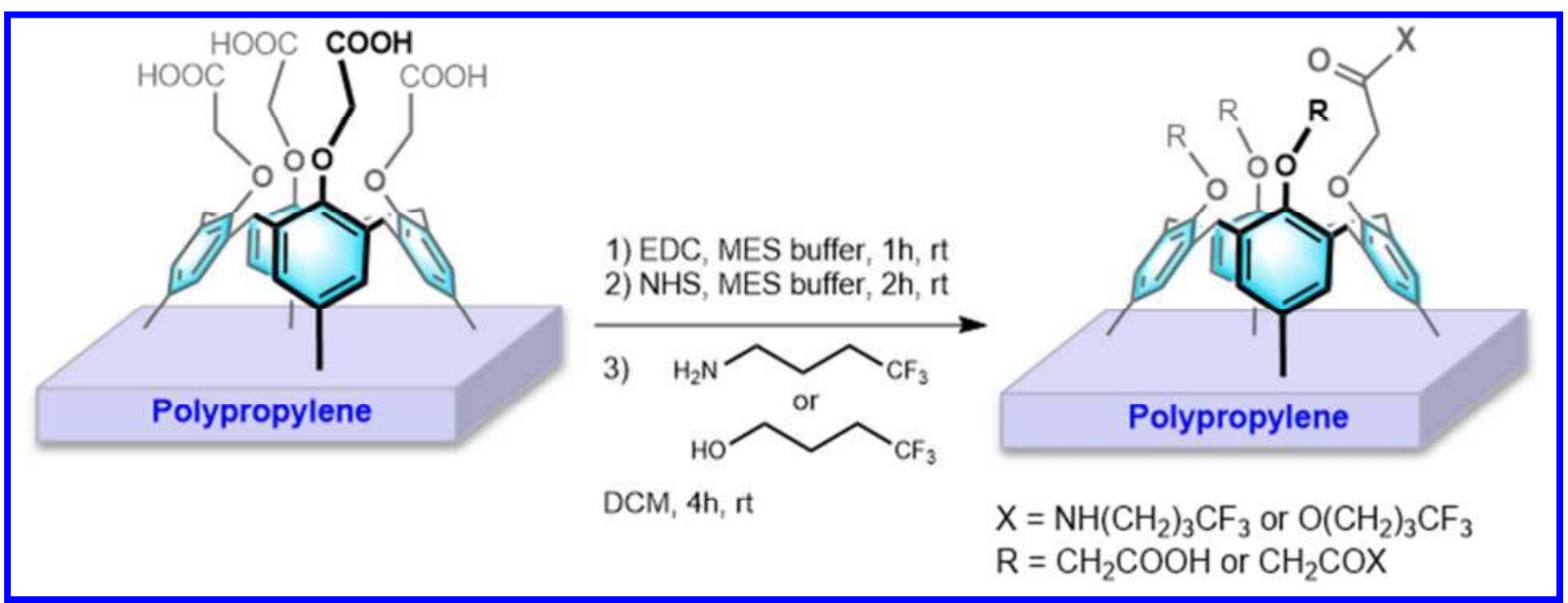

Figure 7. Post-functionalization of polypropylene surfaces modified with compound 2.

The survey spectra of the post-functionalized PP surfaces show main peaks attributed to $\mathrm{C}, \mathrm{O}$ and F elemental species (see SI). In both cases, the presence of F1s photoelectron peaks at 688.5 $\mathrm{eV}$ is a clear indication that the post-functionalization reactions at the PP surfaces were successful. This conclusion is strengthened by the decomposition of the $\mathrm{C} 1 \mathrm{~s}$ core level spectrum showing a component at $293 \mathrm{eV}$, characteristic of $\mathrm{CF}_{3}$ groups (Figure 8). In the $\mathrm{C} 1 \mathrm{~s}$ peak, the main contribution at $285 \mathrm{eV}$ can be attributed to the aliphatic and aromatic carbon atoms of 
calix[4] arene 2 coupled with the trifluorobutyl compounds as well as the carbon atoms from the PP substrate. The C-O-C contribution at $286.3 \mathrm{eV}$ corresponds to the ether groups in the calixarene core but also to contaminant species that are also associated to the $\mathrm{C}=\mathrm{O}$ contribution at $287.3 \mathrm{eV}$, as detected on bare PP samples (see SI). As a result, the atomic ratio of C in C-O$\mathrm{C} / \mathrm{C}$ in $\mathrm{CF}_{3}$ is somewhat higher than the expected theoretical value on the basis of the sole calixarene structure $(4 / 4=1)$ (see Table 1).

Table 1. Atomic ratio evaluated in the $\mathrm{C} 1 \mathrm{~s}$ decomposition fit for the two post-functionalized surfaces.

\begin{tabular}{|cccccc|}
\hline $\begin{array}{c}\text { Samples PP-2 } \\
\text { coupled to }\end{array}$ & Ratio & Ratio & Ratio & Ratio & Ratio \\
\hline trifluorobutanol & 0.15 & 0.085 & 0.05 & 3 & 1 \\
trifluorobutylamine & 0.12 & 0.048 & 0.033 & 3.6 & $0-C=O / C F_{3}$ or $N-C=O / C F_{3}$ \\
\hline
\end{tabular}

A component at 289.2-289.4 eV corresponds to the carbon atoms in amide or ester groups formed after the coupling reaction with the trifluorobutyl compounds or, possibly, to unreacted carboxylic groups. Interestingly, the atomic ratio of $\mathrm{C}$ in this component to $\mathrm{C}$ in $\mathrm{CF}_{3}$ is found to be 1 for the coupling with 4,4,4-trifluoro-1-butanol and equal to 0.7 with 4,4,4trifluorobutylamine. This shows that the chemical coupling is highly efficient, involving 3 to 4 of the reactive carboxylic termini in the same calix platform. This result evidences the possibility to introduce molecular species with a fine spatial control that is imposed by the geometry of the calixarene small rim. 

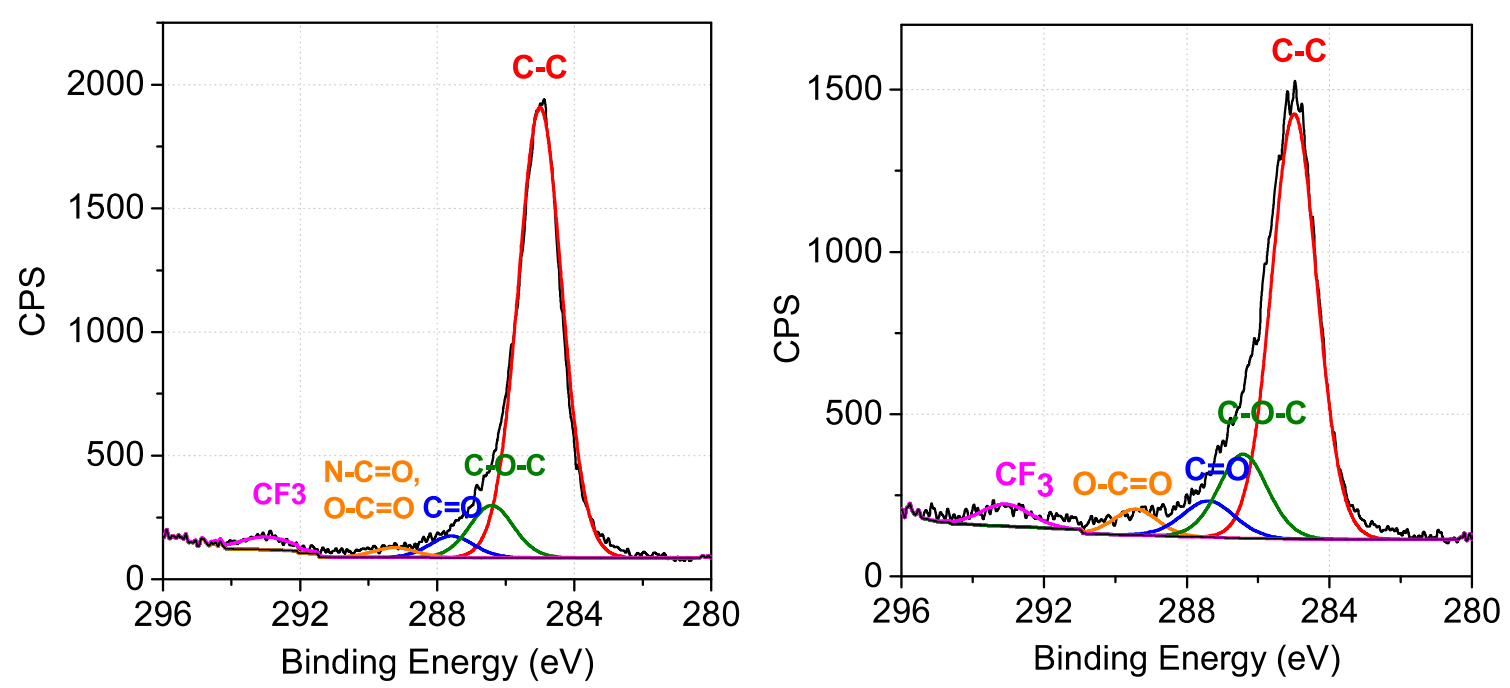

Figure 8. High resolution C1s spectra with insets showing survey spectra of (left) 4,4,4trifluorobutylamine modified surface and (right) 4,4,4-trifluoro-1-butanol modified surface.

All these XPS data demonstrate that the polymer surface could be efficiently postfunctionalized thanks to the calixarene platform. These results show the versatility of the approach for tailoring the PP polymeric surfaces.

Functionalization of other polymeric substrates. Preliminary work was undertaken with other polymeric substrates such as polyethylene terephthalate (PET) and polystyrene (PS) in order to evaluate the generalization of the approach. The different polymer surfaces were modified with calixarene 1, allowing a straightforward characterization from XPS measurements (Figure 9, Tables S1 and S2). The characteristic peak for F1s photoelectrons at $688.5 \mathrm{eV}$ can be clearly observed in the survey spectra for all modified polymers. The decomposition of the C1s core level spectra shows the presence of a peak corresponding to $\mathrm{CF}_{3}(293 \mathrm{eV}, 3.4 \%$ of $\mathrm{C} 1 \mathrm{~s}$ for PET; $293.3 \mathrm{eV}, 4 \%$ of $\mathrm{C} 1 \mathrm{~s}$ for PS). This observation clearly indicates that calix[4]arene 1 was grafted onto these polymeric surfaces. As discussed in the former sections, the main components 
at $285 \mathrm{eV}$ can be attributed to the carbon atoms of the grafted calix[4]arene molecules but also to the aliphatic or aromatic carbon atoms (C-C) from the substrates. The C-O component $(286.3$ $\mathrm{eV}$ ) is due partly to the grafted calixarene compound and to the polymer substrates, as identified onto the bare polymer surfaces (see SI). The higher binding energy components correspond to carbon atoms in the polymer substrates (probably contaminants for PS). Especially, the XPS C1s spectrum of PET (bare) surface gives a characteristic signal, with a relative composition of peaks for $\mathrm{C}-\mathrm{C}, \mathrm{C}-\mathrm{O}-\mathrm{C}$ and $\mathrm{O}-\mathrm{C}=\mathrm{O}$ corresponding to the chemical structure of the PET polymer. Note that a treatment in hydroxide solution prior to analysis does not modify the XPS spectra signature (see Table S1 and S2). After grafting the calixarene platform onto the PET surface, the typical spectrum of PET is still observed, showing that the grafted calixarene layer is necessarily thin. This observation is fully consistent with the AFM study. ${ }^{72}$
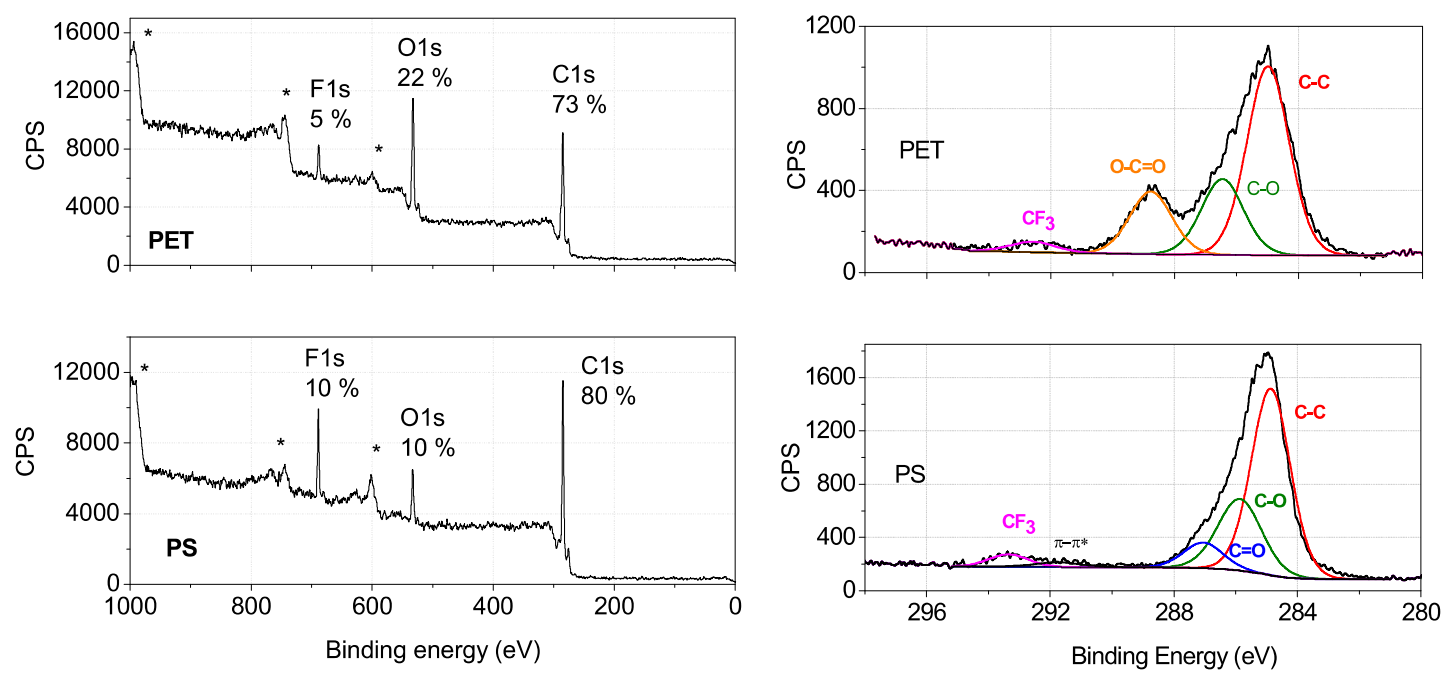

Figure 9. Survey spectra (left) and high resolution C1s spectra (right) of polymers (PS and PET) modified with calix[4]arene 1. * denotes Auger peaks.

\section{Conclusion}


We have reported here a systematic study of the sodium hydroxide-based grafting of diazonium salts on gold and polymer surfaces, producing the corresponding reactive diazoate salt. Two different calix[4]arene-tetradiazonium salts $\mathbf{1}$ and $\mathbf{2}$ as well as a classical aryldiazonium salt 3 were used to evaluate the efficiency of this approach. Being rarely employed, this grafting method was first validated on gold substrates from comparison with the well-known electrografting procedure. AFM and ellipsometry measurements indicate that a compact monolayer of calix[4]arenes is obtained, in agreement with our previous study based on the electrochemical procedure. In contrast, the diazonium salt $\mathbf{3}$ has led to the formation of a multilayered film on gold, as expected. We then transposed this sodium hydroxide-based grafting procedure on insulating polymers, focusing mainly on polypropylene. Polypropylene surface was successfully modified with the diazonium salt $\mathbf{3}$ in a multilayer fashion as indicated by atomic force microscopy (AFM), while the calix[4]arenes compounds $\mathbf{1}$ and $\mathbf{2}$ were shown to produce thinner films at the polymer surface. The hydroxide-based grafting of the calix[4]arenetetradiazonium salts on polypropylene was further confirmed by X-ray photoelectron spectroscopy (XPS) measurements. The strategy was successfully extended to other polymer substrates including polystyrene and polyethylene terephthalate. Finally, as a proof of concept, the post-functionalization of the polypropylene surfaces modified by the calix[4]arene decorated with carboxylic appending arms was easily achieved. These results highlight the powerful technique that is the grafting of diazonium in sodium hydroxide for the modification of polymers. This method is particularly simple to operate and does not require complex and costly equipment like, for instance, for plasma methods. It indeed only necessitates dipping polymer samples in a solution containing the diazonium salts. Using this technique, we have gained further access and understanding of the modification and post-functionalization of insulating 
materials. The use of the calix[4]arene platform permits a further fine molecular control of the polymeric surface modification, allowing to i) modify surface properties of polymers without drastic modifications of their bulk properties, ii) introduce a large range of chemical objects (including biomolecules, chromophores, nanoparticles, ...). These results open real possibilities in the tailoring of polymers properties.

\section{ASSOCIATED CONTENT}

Supporting Information. Ellipsometry measurements on gold, XPS measurements of bare polymeric surfaces and post-functionalized polypropylene surfaces, XPS data tables for all the polymer surfaces. This material is available free of charge via the Internet at http://pubs.acs.org.

\section{AUTHOR INFORMATION}

\section{Corresponding Author}

*E-mail: corinne.lagrost@univ-rennes1.fr

Phone : +33223235940

*E-mail: amattiuz@ulb.ac.be

Phone : +32 26502474

\section{Author Contributions}

The manuscript was written through contributions of all authors. All authors have given approval to the final version of the manuscript.

\section{ACKNOWLEDGMENT}


The authors would like to thank Pascale Blond for the generous gift of compound $\mathbf{3}$ and Delphine Merche for performing control XPS measurements. JH thanks the FNRS (Belgian National Fund for Scientific Research) for an "Aspirant Grant". FR and JH also thank the Belgian Federal Office for Science Policy (BELSPO) for financial support to the I.A.P (Interuniversity Attraction Pole) programs "PSI _ Physical Chemistry of Plasma Surface Interactions -IAP-VII/12, P7/34-. AM and LTG thank the Région Wallonne for financial support to the "FIRST Spin-off MONOCAL" grant.

\section{REFERENCES}

(1) Bélanger, D.; Pinson, J. Electrografting: A Powerful Method for Surface Modification. Chem. Soc. Rev. 2011, 40, 3995-4048.

(2) Mahouche-Chergui, S.; Gam-Derouich, S.; Mangeney, C.; Chehimi, M. M. Aryl Diazonium Salts: A New Class of Coupling Agents for Bonding Polymers, Biomacromolecules and Nanoparticles to Surfaces. Chem. Soc. Rev. 2011, 40, 4143-4166.

(3) Berisha, A.; Chehimi, M.M.; Pinson, J.; Podvorica, F. in Electroanalytical Chemistry. A Series of Advances, Eds. A.J. Bard, C.G. Zoski, vol 26, chapter 3, pp 115-222

(4) Flavel, B. S.; Garrett, D. J.; Lehr, J.; Shapter, J. G.; Downard, A. J. Chemically Immobilised Carbon Nanotubes on Silicon: Stable Surfaces for Aqueous Electrochemistry. Electrochim. Acta 2010, 55, 3995- 4001.

(5) Betelu, S.; Vautrin-U1, C.; Chaussé, A. Novel 4-Carboxyphenyl-Grafted Screen-Printed Electrode for Trace $\mathrm{Cu}$ (II) Determination. Electrochem. Commun. 2009, 11, 383- 386.

(6) Betelu, S.; Vautrin-Ul, C.; Ly, J.; Chaussé, A. Screen-Printed Electrografted Electrode for Trace Uranium Analysis. Talanta 2009, 80, 372-376.

(7) Chergui, S. M.; Abbas, N.; Matrab, T.; Turmine, M.; Bon Nguyen, E.; Losno, R.; Pinson, J.; Chehimi, M. M. Uptake of Copper Ions by Carbon Fiber/Polymer Hybrids Prepared by 
Tandem Diazonium Salt Chemistry and In Situ Atom Transfer Radical Polymerization. Carbon, 2010, 48, 2106-2111.

(8) Pchelintsev, N. A.; Millner, P. A. Development of Surface Activated Screen-Printed Carbon Transducers for Biosensors Application. Anal. Lett. 2007, 40, 1317-1332.

(9) Griveau, S.; Mercier, D.; Vautrin-Ul, C.; Chaussé, A. Electrochemical Grafting by Reduction of 4-aminoethylbenzenediazonium Salt: Application to the Immobilization of (bio) molecules. Electrochem. Commun. 2007, 7, 2768-2773.

(10) Alonso-Lomillo, M. A.; Rüdiger, O.; Maroto-Valiente, A.; Velez, M.; Rodriguez-Ramos, I.; Javier Muñoz, F.; Fernàndez, V. M.; De Lacey, A. L. Hydrogenase-Coated Carbon Nanotubes for Efficient $\mathrm{H}_{2}$ Oxidation. Nano Lett. 2007, 7, 1603-1608.

(11) Kullapere, M.; Kozlova, J.; Matisen, L.; Sammelselg, V.; Menezes, H. A.; Maia, G.; Schiffrin, D. J.; Tammeveski, K. Electrochemical Properties of Aryl-Modified Gold Electrodes. J. Electroanal. Chem. 2010, 641, 90-98.

(12) Aswal, D. K.; Koiry, S. P.; Jousselme, B.; Gupta, S. K.; Palacin, S.; Yakhmi, J. V. Hybrid Molecule-on-Silicon Nanoelectronics: Electrochemical Processes for Grafting and Printing of Monolayers. Phys. E. 2009, 41, 325- 344.

(13) Hersam, M. C. Progress toward Monodisperse Single-Walled Carbon Nanotubes. Nat. Nanotechnol. 2008, 3, 387- 394.

(14) Lu, F.; Gu, L.; Meziani, M. J.; Wang, X.; Luo, P. G.; Veca, L. M.; Cao, L.; Sun, Y.-P. Advances in Bioapplications of Carbon Nanotubes. Adv. Mater. 2009, 21, 139 - 152.

(15) Singh, P.; Campidelli, S.; Giordani, S.; Bonifazi, D.; Bianco, A.; Prato, M. Organic Functionalisation and Characterisation of Single-Walled Carbon Nanotubes. Chem. Soc. Rev. 2009, 38, 2214-2230.

(16) Greenwood, J.; Phan, T. H.; Fujita, Y.; Li, Z.; Ivasenko, O.; Vanderlinden, W.; Van Gorp, H.; Frederickx, W.; Lu, G.; Tahara, K.; et al; Covalent Modification of Graphene and 
Graphite Using Diazonium Chemistry: Tunable Grafting and Nanomanipulation. ACS Nano 2015, 9, 5520-5535.

(17) Pan, Q.; Wang, H.; Jiang, Y. Natural Graphite Modified with Nitrophenyl Multilayers as Anode Materials for Lithium Ion Batteries. J. Mater. Chem. 2007, 17, 329-334.

(18) Martin, C.; Alias, M.; Christien, F.; Crosnier, O.; Bélanger, D.; Brousse, T. GraphiteGrafted Silicon Nanocomposite as a Negative Electrode for Lithium-Ion Batteries. Adv. Mater. 2009, 21, 4735-4741.

(19) Assresahegn, B. D.; Brousse, T.; Bélanger, D. Advances on the Use of Diazonium Chemistry for Functionalization of Materials Used in Energy Storage Systems. Carbon 2015, 92, 362-381.

(20) Belmont, J.A.; Bureau, C.; Chehimi, M.M.; Gam-Derouich, S.; Pinson, J. Patents and Industrial Applications of Aryldiazonium Salts and Other Coupling Agents, in Aryl Diazonium Dalts. New Coupling Agents in polymer and surface science, ed. M.M. Chehimi, Wiley-VCH, Weinheim, 2012.

(21) Picot, M.; Rodulfo, R.; Szymczyk, A.; Barrière, F.; Rabiller-Baudry, M. A Versatile Route to Modify Polyethersulfone Membranes by Chemical Reduction of Aryldiazonium Salts. J. Membrane Sci. 2012, 417-418, 131-136.

(22) Mesnage, A.; Esnouf, S.; Jégou, P.; Deniau, G.; Palacin, S. Understanding the RedoxInduced Polymer Grafting Process: a Dual Surface-Solution Analysis. Chem. Mater. 2010, $22,6229-6239$

(23) Mévellec, V.; Roussel, S.; Tessier, L.; Chancolon, J.; Mayne-L’Hermite, M.; Deniau, G.; Viel, P.; Palacin, S. Grafting Polymers on Surfaces: A New Powerful and Versatile Diazonium Salt-Based One-Step Process in Aqueous Media. Chem. Mater. 2007, 19, 63236330. 
(24) Torréns, M.; Ortiz, M.; Turner, A. P. F.; Beni, V.; O’sullivan, C. K. Controlled ZnMediated Grafting of Thin Layers of Bipodal Diazonium Salt on Gold and Carbon Substrates. Chem. Eur. J. 2015, 21, 671-681.

(25) Torréns, M.; Ortiz, M.; Bejarano-Nosas, D.; O'sullivan, C. K. Electrochemiluminescent DNA Sensor Based on Controlled Zn-Mediated Grafting of Diazonium Precursors. Anal. Bioanal. Chem. 2015, 407, 5579-5586.

(26) Bouriga, M.; Chehimi, M.M.; Combellas, C.; Decorse, P.; Kanoufi, F.; Deronzier, A.; Pinson, J. Sensitized Photografting of Diazonium Salts by Visible Light. J. Chem. Mater. 2013, 25, 90-97.

(27) Bravo-Diaz, C. Diazo ethers: Formation and Decomposition in the Course of Reactions between Arenediazonium Ions and Different Alcohols. Mini-Rev. Org. Chem. 2009, 6, $105-$ 113.

(28) Sienkiewicz, A.; Szymula, M.; Narkiewicz-Michalek, J.; Bravo-Díaz, C. Formation of Diazohydroxides $\mathrm{ArN}_{2} \mathrm{OH}$ in Aqueous Acid Solution: Polarographic Determination of the Equilibrium Constant $\mathrm{K}_{\mathrm{R}}$ for the Reaction of 4-substitutedarenediazonium Ions with $\mathrm{H}_{2} \mathrm{O}$. J. Phys. Org. Chem. 2013, 27, 284-289.

(29) Lehr, J.; Williamson, B. E.; Flavel, B. S.; Downard, A. J.; Reaction of Gold substrates With Diazonium Salts in Acidic Solution at Open-Circuit Potential. Langmuir 2009, 25, 13503-13509.

(30) Hurley, B. L.; McCreery, R. L. Covalent Bonding of Organic Molecules to $\mathrm{Cu}$ and $\mathrm{Al}$ Alloy 2024 T3 Surfaces via Diazonium Ion Reduction. J. Electrochem. Soc. 2004, 151, B252-B259.

(31) Chamoulaud, G.; Bélanger, D. Spontaneous Derivatization of a Copper Electrode with In Situ Generated Diazonium Cations in Aprotic and Aqueous Media. J. Phys. Chem. C, 2007, 111, 7501-7507. 
(32) Combellas, C.; Delamar, M.; Kanoufi, F.; Pinson, J.; Podvorica, F. I. Spontaneous Grafting of Iron Surfaces by Reduction of Aryldiazonium Salts in Acidic or Neutral Aqueous Solution. Application to the Protection of Iron against Corrosion. Chem. Mater. 2005, 17, 3968-3975.

(33) Adenier, A.; Barré, N.; Cabet-Deliry, E.; Chaussé, A.; Griveau, S.; Mercier, F.; Pinson, J.; Vautrin-Ul, C. Study of the Spontaneous Formation of Organic Layers on Carbon and Metal Surfaces from Diazonium Salts. Surf. Sci. 2006, 600, 4801-4812.

(34) Doyle, C.D.; Rocha, J-D. R.; Weisùan, R.B.; Tour, J.M. Structure-Dependent Reactivity of Semiconducting Single-Walled Carbon Nanotubes with Benzenediazonium Salts. J. Am. Chem. Soc. 2008, 130, 6795-6800.

(35) Podvorica, F.I.; Kanoufi, F.; Pinson, J.; Combellas, C. Spontaneous Grafting of Diazoates on Metals. Electrochim. Acta 2009, 54, 2164-2170.

(36) Griffete, N.; Herbst, F.; Pinson, J.; Ammar, S.; Mangeney, C.; Preparation of WaterSoluble Magnetic Nanocrystals Using Aryl Diazonium Salt Chemistry. J. Am. Chem. Soc. 2011, 133, 1646-1649.

(37) Hegarty, A.F. in The Chemistry of Diazonium and Diazo Goups, Part 2; Patai, S., Ed. John Wiley and Sons, 1978, p511.

(38) Goddard, J.M.; Hotchkiss, J.H. Polymer Surface Modification for the Attachment of Bioactive Compounds. Prog. Polym. Sci. 2007, 32, 698-725.

(39) Karnik, R.; Gu, F.; Basto, P. Cannizzaro, C.; Dean, L.; Kyei-manu, W.; Langer, R.; Farokhzad, O.C. Microfluidic Platform for Controlled Synthesis of Polymeric Nanoparticles. Nano Lett. 2008, 8, 2906-2912.

(40) Perréard, C.; Ladner, Y.; d’Orlyé, F.; Descroix, S.; Taniga, V.; Varenne, A.; Kanoufi, F.; Slim, C.; Griveau, S.; Bedioui, F. Two-Step Local Functionalization of Fluoropolymer Dyneon THV Microfluidic Materials by Scanning Electrochemical Microscopy Combined to Click Reaction. F. RSC Adv. 2015, 5, 11128-11131. 
(41) Awaja, F.; Gilbert, M.; Kelly, G.; Fox, B.; Pigram, P.J. Adhesion of polymers. Prog. Polym. Sci. 2009, 34, 948-968.

(42) Yang, Y.F.; Li, Y.; Li, Q-L; Wan, L-S.; Xu, Z. K. Surface Hydrophilization of Microporous Polypropylene Membrane by Grafting Zwitterionic Polymer for AntiBiofouling. J. Membr. Sci. 2010, 362, 255-264.

(43) Chehimi, M.M.; Lamouri, A.; Picot, M.; Pinson, J. Surface modification of Polymers by Reduction of Diazonium Salts: Polymethylmethacrylate as an Example. J. Mater. Chem. C 2014, 2, 356-363.

(44) Combellas, C.; Kanoufi, F.; Mazouzi, D.; Thiébault, A.; Bertrand, P.; Médard, N. Surface Modification of Halogenated Polymers. 4. Functionalisation of Poly (tetrafluoroethylene) Surfaces by Diazonium Salts. Polymer, 2003, 44, 19-24.

(45) Le, X.; Viel, P.; Jégou, P.; Garcia, A.; Berthelot, T.; Bui, T.H.; Palacin, S. DiazoniumInduced Anchoring Process: an Application to Improve the Monovalent Selectivity of Cation Exchange Membranes. J. mater. Chem. 2010, 20, 3750-3757.

(46) Picot, M.; Rodulfo, R.; Szymczyk, N.A.; Barrière, F.; Rabiller-Baudry, M. A Versatile Route to Modify Polyethersulfone Membranes by Chemical Reduction of Aryldiazonium Salts. J. Membr. Sci. 2012, 417-418, 131-136.

(47) Brisset, F.; Vieillard, J.; Berton, B.; Morin-Grognet, S.; Duclairoir-Poc, C. L.; Le Derf, F. Surface Functionalization of Cyclic Olefin Copolymer With Aryldiazonium Salts: A Covalent Grafting Method. Appl. Surf. Sci. 2015, 329, 337-346.

(48) Garcia, A; Hanifi, N.; Jousselme, B.; Jégou, P.; Palacin, S.; Viel, P.; Berthelot, T. Polymer Grafting by Inkjet Printing: a Direct Chemical Writing Toolset. Adv. Func. Mater. 2013, 23, 3668-3674.

(49) Combellas, C.; Kanoufi, F.; Pinson, J.; Podvorica, F. I. Sterically Hindered Diazonium Salts for the Grafting of a Monolayer on Metals. J. Am. Chem. Soc. 2008, 130, 8576-8577. 
(50) Leroux, Y. R.; Fei, H.; Noel, J.-M.; Roux, C.; Hapiot, P. Efficient Covalent Modification of a Carbon Surface: Use of a Silyl Protecting Group to Form an Active Monolayer. J. Am. Chem. Soc. 2010, 132, 14039-14041.

(51) Malmos, K.; Dong, M.; Pillai, S.; Kingshott, P.; Besenbacher, F.; Pedersen, S. U.; Daasbjerg, K. Using a Hydrazone-Protected Benzenediazonium Salt to Introduce a NearMonolayer of Benzaldehyde on Glassy Carbon Surfaces. J. Am. Chem. Soc. 2009, 131, 4928-4936.

(52) Nielsen, L. T.; Vase, K. H.; Dong, M.; Besenbacher, F.; Pederson, S. U.; Daasbjerg, K. Electrochemical Approach for Constructing a Monolayer of Thiophenolates from Grafted Multilayers of Diaryl Disulfides ; J. Am. Chem. Soc., 2007, 129, 1888-1889.

(53) Peng, Z.; Holm, A. H.; Nielsen, L. T.; Pedersen, S. U.; Daasberg, K. Covalent Sidewall Functionalization of Carbon Nanotubes by a "Formation- Degradation" Approach. Chem. Mater. 2008, 20, 6068-6075.

(54) Menanteau, T.; Levillain, E.; Breton, T. Electrografting via Diazonium Chemistry: From Multilayer to Monolayer Using Radical Scavenger. Chem. Mater. 2013, 25, 2905-2909.

(55) Menanteau, T.; Levillain, E.; Downard, A. J.; Breton, T. Evidence of Monolayer Formation via Diazonium Grafting With a Radical Scavenger: Electrochemical, AFM and XPS Monitoring. Phys. Chem. Chem. Phys. 2015, 17, 13137-13142.

(56) Doppelt, P.; Hallais, G.; Pinson, J.; Podvorica, F.; Verneyre, S. Surface Modification of Conducting Substrates. Existence of Azo Bonds in the Structure of Organic Layers Obtained From Diazonium Salts; Chem. Mater. 2007, 19, 4570-4575

(57) Andrieux, C. P.; Pinson, J. The Standard Redox Potential of the Phenyl Radical/Anion Couple. J. Am. Chem. Soc. 2003, 125, 14801-14806.

(58) Zigah, D.; Noel, J.-M.; Lagrost, C.; Hapiot, P. Charge Transfer between Electroactive Species Immobilized on Carbon Surfaces by Aryl Diazonium Reduction. SECM Investigations. J. Phys. Chem. C 2010, 114, 3075-3081. 
(59) Love, C. J.; Estroff, L. A.; Kriebel, J. K.; Nuzzo, R. G.; Whitesides, G. M. SelfAssembled Monolayers of Thiolates on Metals as a Form of Nanotechnology. Chem. Rev. 2005, 105, 1103-1169.

(60) Mattiuzzi, A.; Jabin, I.; Mangeney, C.; Roux, C.; Reinaud, O.; Santos, L.; Bergamini, J.F.; Hapiot, P.; Lagrost, C. Electrografting of Calix[4]arenediazonium Salts to Form Versatile Robust Platforms for Spatially Controlled Surface Functionalization. Nat. Commun. 2012, 3, 1130.

(61) Santos, L.; Mattiuzzi, A.; Jabin, I.; Vandecasteele, N.; Reniers, F.; Reinaud, O.; Hapiot, P.; Lhenry, S.; Leroux, Y.; Lagrost, C. One-Pot Electrografting of Mixed Monolayers with Controlled Composition. J. Phys. Chem. C 2014, 118, 15919-15928.

(62) Troian-Gautier, L.; Valkenier, H.; Mattiuzzi, A.; Jabin, I.; Van den Brande, N.; Van Mele, B.; Hubert, J. ; Reniers, F. ; Bruylants, G. ; Lagrost, C. et al. Extremely Robust and Post-Functionalizable Gold Nanoparticles Coated with Calix[4]arenes via Metal-Carbon Bonds, Chem. Commun. 2016, 52, 10493-10496.

(63) Bourdillon, C.; Delamar, M.; Demaille, C.; Hitmi, R.; Moiroux, J.; Pinson, J.Immobilization of Glucose Oxidase on a Carbon Surface Derivatized by Electrochemical Reduction of Diazonium Salts. J. Electroanal. Chem. 1992, 336, 113-123.

(64) Anariba, F.; DuVall, S. H.; McCreery, R. L. Mono-and Multilayer Formation by Diazonium Reduction on Carbon Surfaces Monitored with Atomic Force Microscopy "Scratching". Anal. Chem. 2003, 75, 3837-3844.

(65) Theoretical heights of the molecules were estimated by MM2 energy minimization using ChemBio 3D Ultra 12.0 Software, CambridgeSoft Corporation.

(66) Tao, H.T.; Xiong, X.-G.; Dau, P.D.; Wang, Y.-L.; Huang, D.L.; Li, J.; Wang, L.-S. Probing the Nature of Gold-Carbon Bonding in Gold-Alkynyl Complexes. Nat. Commun. 2013, 4, 2223. 
(67) Baranton, S.; Bélanger, D. Electrochemical Derivatization of Carbon Surface by Reduction of In Situ Generated Diazonium Cations. J. Phys. Chem. B 2005, 109, 2440124410.

(68) Toupin, M.; Bélanger, D. Thermal Stability Study of Aryl Modified Carbon Black by In Situ Generated Diazonium Salt. J. Phys. Chem. C 2007, 111, 5394-5401.

(69) Saby, C.; Ortiz, B.; Champagne, G. Y.; Bélanger, D. Electrochemical Modification of Glassy Carbon Electrode Using Aromatic Diazonium Salts. 1. Blocking Effect of 4nitrophenyl and 4-carboxyphenyl Groups. Langmuir, 1997, 13, 6805-6813.

(70) Pazo-Llorente, R.; Bravo-Diaz, C.; Gonzalez-Romero, E. pH Effects on Ethanolysis of some Arenediazonium ions: Evidence for Homolytic Dediazoniation proceeding through Formation of Transient Diazo Ethers. Eur. J. Org. Chem. 2004, 15, 3221-3226.

(71) The spontaneous dediazonation of methylbenzenediazonium salts in basic medium through the formation of diazohydroxides and diazoates has been shown to occur via an homolytic pathway ${ }^{70}$, with an apparent kinetic rate constant $\mathrm{k}_{\mathrm{obs}} \approx 5 \times 10^{-3} \mathrm{~s}^{-1}$ at $60^{\circ} \mathrm{C}$ (in $20 \% \mathrm{EtOH} / \mathrm{H}_{2} \mathrm{O}$ ). This could roughly correspond to $\mathrm{k}_{\mathrm{obs}} \approx 3-4 \times 10^{-4} \mathrm{~s}^{-1}$ at $20^{\circ} \mathrm{C}$ (considering an activation energy of $60 \mathrm{~kJ} \mathrm{~mol}^{-1}$, which is a reasonable average value for this kind of reaction). An half-time decay equal to $1730-2300 \mathrm{~s}$ for the diazoate could be deduced from this value

(72) Similar observations could be drawn from the comparison of XPS spectra of bare PP or PS and the functionalized surfaces. However, the corresponding $\mathrm{C} 1 \mathrm{~s}$ signals for these polymers are much less characteristic, making it difficult to get a clear cut conclusion. 
TOC Graphic

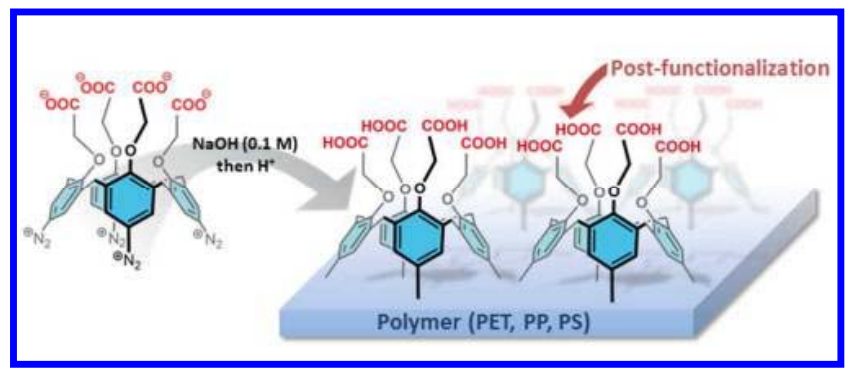

ACS Paragon Plus Environment 